UNDERGRADUATE RESEARCH IN NATURAL AND CLINICAL SCIENCE AND TECHNOLOGY (URNCST) JOURNAL Read more URNCST Journal articles and submit your own today at: https://www.urncst.com

\title{
Scinapse 2020-2021 Undergraduate Science Case Competition: Antimicrobial Resistance: A Global Health Crisis
}

\author{
Clarissa Ngo, BSc Student [1]*, Rebecca Krnel, BSc Student [1], Linda Mardiros, BSc [2] \\ [1] Faculty of Science, University of Ottawa, Ottawa, ON, Canada \\ [2] Faculty of Medicine, University of Ottawa, Ottawa, ON, Canada \\ *Corresponding Author: cngo016@uottawa.ca
}

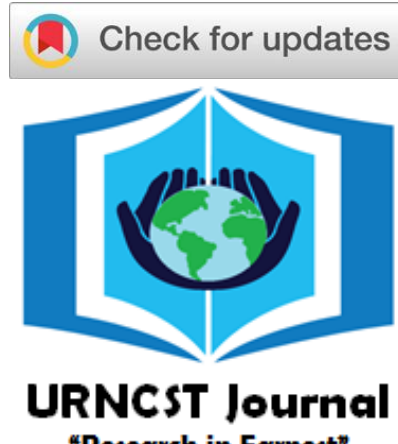

\begin{abstract}
The Scinapse Undergraduate Science Case Competition (USCC) provides an opportunity for undergraduate students to experience the development of a novel research proposal. A case is presented to all participants and, using in-depth literature search (publications, reports, studies and published writings), students connect and pinpoint key elements allowing them to develop a hypothesis in support of the case in question. Participants also develop a methodology which will test the validity of their hypothesis. This year's case topic focused on antimicrobial resistance as a major threat to global health that requires a complex, multifaceted response. In teams of 2-4, undergraduate students tackled the case and provided novel research ideas that may hold the key to combating the global spread of antimicrobial resistance. In total, the 2019-2020 USCC attracted 694 undergraduate students from 19 universities across Canada and the United States. The top 10\% of written submissions are highlighted in this abstract booklet.
\end{abstract}

Keywords: antimicrobial resistance; undergraduate research; science case competition

Table of Contents

Lower Division. pg. A01-A06

Upper Division pg. A06-A10

\section{Conference Abstracts}

Note: These abstracts have been reproduced directly from the material supplied by the authors, without editorial alteration by the staff of the URNCST Journal. Insufficiencies of preparation, grammar, spelling, style, syntax, and usage are the authors.

\section{$\underline{\text { Lower Division }}$}

Fusion between membrane-penetrating peptide tag and bacteriophage endolysin $\mathrm{T} 5$ to increase antibacterial effectiveness against gram-negative bacteria Alex Huynh [1], Eric Zhang [1], Dalraj Dhillon [1], Dhairya Bhatt [1] [1] McMaster University, Hamilton, Ontario, Canada L8S 4L8

Antibiotic resistance has been recognized as one of the world's most problematic public health issues. As more strains of bacteria develop increased resistance, bacterial infections become increasingly difficult to treat with common antibiotics. The bacteria-lysing enzyme "Endolysin", involved in the bacteriophage reproduction cycle, has been shown to be a viable alternative treatment against antibiotic-resistant gram-positive bacteria. However, an additional outer membrane in gramnegative bacteria prevents endolysins from disrupting the inner peptidoglycan layer when applied extracellularly, rendering most endolysins ineffective. Modified endolysins, fortunately, have been shown to have lytic properties against gramnegative bacteria. This proposal aims to test the bactericidal efficacy of a new recombinant (modified) endolysin EndoT5xCtn[15-34] against E. coli and Pseudomonas aeruginosa, two strains of highly resistant gram-negative bacteria. Formed by adding ctn[15-34], a membrane-penetrating protein tag, to Endolysin T5, which specifically targets the peptidoglycan layer of gram-negative bacteria, the resultant EndoT5-ctn[15-34] recombinant protein is able to penetrate the outer membrane, and subsequently destabilize the peptidoglycan layer and cause apoptosis. Additionally, the components of this specific recombinant protein individually have low hemolytic activity and high thermal stability, which allows for potential 
UNDERGRADUATE RESEARCH IN NATURAL AND CLINICAL SCIENCE AND TECHNOLOGY (URNCST) JOURNAL Read more URNCST Journal articles and submit your own today at: https://www.urncst.com

therapeutic applications. Endolysin therapy may also be more efficacious and less prone to antimicrobial resistance, as the lysing capabilities are direct and immediate on essential components as opposed to reliant on stages of cellular development. This novel therapy can be considered as a viable alternative to drastically reduce antimicrobial resistance and become a powerful and flexible antibiotic against both resistant gram-positive and gram-negative bacteria.

To resist or not to resist: An AgNP depolymerase-TFD conjugate therapy for K. Pneumoniae Mira Ishak [1], Jonathan Monteiro [1], Anjelica Shrestha [1], Sneha Mukherjee [1] [1] McMaster University, Hamilton, Ontario, Canada L8S 4L8

The rapid emergence of multidrug resistance in Klebsiella pneumoniae (K. pneumoniae) has threatened public health across the world, as more bacterial strains evolve resistance mechanisms against widely-used antibiotics. This proposal aims to test a novel delivery system for DNA aptamers, specifically, Transcription Factor Decoys (TFDs) that prevent the expression of vital genes under the control of sigma factor 70. Since the primary mechanism of resistance for clinical Klebsiella strains are their capsule polysaccharide (CPS), TFDs will be delivered to bacterial cells with a silver nanoparticle (AgNP) conjugated to a bacteriophage polysaccharide depolymerase that will target this CPS. K. pneumoniae phage (K-phage) polysaccharide depolymerase in conjunction with the AgNP will lead to direct cleavage of the capsulated domain of Klebsiella. The TFD aptamer targets the binding sites of the sigma 70 transcription factor to arrest the synthesis of proteins that are essential for cell survival. Targeting bacterial transcriptional mechanisms allows for the inhibition of a broad array of genes required for nutrition, instead of one component of a pathway that can be mutated to confer resistance. Our approach also analyzes the efficacy of AgNPs and K-phage depolymerase in delivering such antimicrobial TFDs to counteract capsular resistance. By subverting various resistance mechanisms, our novel-multifaceted therapy has the potential to overcome many of the current challenges faced in the treatment of antibiotic-resistant infections.

Influence of perinatal antibiotics on emergence of antimicrobial resistance in the gut microbiota Ahmed Al-Kayyali [1], Sina Norouzi [1], June Chen [1], Kenisha Arora [1]

[1] Western University, London, Ontario, Canada N6A $3 K 7$

The emergence and spread of antimicrobial resistance is becoming a major threat to global health, food security, and development following its initial usage to combat bacterial infections. Currently antibiotics are being widely administered to treat various perinatal illnesses. Therefore, it is important to investigate the impacts of such treatments on human health outcomes. For instance, previous research has shown that the use of antibiotics can promote development of antimicrobial resistant genes in the gut microbiota. However, this relationship is not fully understood in the context of infant microbiota development. Thus, the aim of this investigation is to better understand the influence of perinatal antibiotics in the emergence of antimicrobial resistance in the gut microbiota. It is predicted that administration of intrapartum antibiotics will result in fewer AMR genes when compared to administration of antibiotics to a developed microbiome. A sample of 12 germ free $\mathrm{BALB} / \mathrm{c}$ mice will be obtained and kept in their isolators for two weeks. After, they will be orally administered a human microbiome (chosen using a set criteria) and breeding of the mice will occur. The female mice will then be randomly allocated into three experimental groups, differing by time of antibiotic administration: intrapartum administration of antibiotics, administration of antibiotics to offspring of 12 weeks of age, and a control group with no antibiotic administration. The DNA will then be extracted from fecal samples and the Basic Local Alignment Search Tool will be used to detect the presence of Beta-lactam antibiotic resistant genes.

Novel synthetic immunotherapeutics for treatment of multidrug-resistant Candida auris

Jeng-liang Wu [1], Justin Yang [1]

[1] Western University, London, Ontario, Canada N6A $3 K 7$

Candida auris is an emerging multidrug-resistant yeast pathogen that can cause invasive infections in hospitalized or immunocompromised patients, an issue which has only become more prevalent during the COVID-19 pandemic. Biofilm formation plays a key role in its resistance to most antifungal agents and ability to survive on the surfaces of medical devices. This paper proposes the synthesis of a novel heterobifunctional immunotherapeutic agent which will both disrupt fungal biofilms and re-engage components of the immune system, targeting $C$. auris through two separate pathways and greatly lowering the chance of resistance. Conjugates will be assembled by linking a compound known for potent antibiofilm and antifungal activity (termed "small molecule biofilm disruptor", or SMBD), to a rhamnose epitope via polyethylene glycol

Ngo et al. | URNCST Journal (2021): Volume 5, Issue 3

DOI Link: https://doi.org/10.26685/urncst.251

Page A2 of A11 
UNDERGRADUATE RESEARCH IN NATURAL AND CLINICAL SCIENCE AND TECHNOLOGY (URNCST) JOURNAL Read more URNCST Journal articles and submit your own today at: https://www.urncst.com

(PEG) spacers. The potential efficacy of the conjugate molecule against $C$. auris infection will be assessed in vitro through its antifungal activity, ability to prevent biofilm formation and disrupt mature biofilms, and ability to induce opsonization. Furthermore, the effect of PEG spacer length will be investigated to determine the optimal chain length for the conjugate molecule. The paper expects to find that treatment with the conjugate agent will lead to greater disruption of biofilms, increased killing of $C$. auris, and increased binding to anti-rhamnose antibodies. Longer PEG spacers are expected to enhance the conjugate's activity. This novel immunotherapeutic can be considered a preliminary step in overcoming antifungal resistance and could potentially pave the way for a new framework to combat multidrug-resistant fungal infections such as $C$. auris.

CRISPR/Cas-mediated pathogenesis disruption to sustainably combat multidrug-resistant pathogens Nathan Biniam [1], Derek Fraser-Halberg [1], Albert Nitu [1]

[1] University of Ottawa, Ottawa, Ontario, Canada K1N 6N5

Antimicrobial resistance (AMR) is an emerging health crisis that threatens global health and prosperity. Despite the emergence of novel antimicrobials, all current approaches eliminate microbiomes crucial to proper host metabolic function and are increasingly becoming associated with diseases such as obesity, diabetes, cardiovascular disease, and other metabolic disorders. This project explores a novel CRISPR/Cas- based approach to targeting and disabling bacterial virulence as a pathogen-specific alternative to antibiotics. The CRISPR-Cas9 nuclease is used to cleave and degrade the pWR100 virulence plasmid of Shigella, and the newly characterized INTEGRATE transposon insertion CRISPR system is used to disable the SPI-1 pathogenicity island of Salmonella through transposon insertion. The latter approach also allows for the insertion of customizable DNA cargo into specific pathogenic loci, which is applied to selectively eliminate Salmonella biofilms through a rationally engineered D-enantiomeric DJK-5 anti-biofilm peptide. Ultimately, both plasmid and chromosomal virulence systems are targeted and eliminated using a novel, multi-faceted CRISPR approach. This ensures that host microbiomes necessary for normal physiological function are not disrupted, and dramatically reduces potential bacterial resistance - all while providing an effective, targeted weapon against emerging drug-resistant pathogens.

Exploring the use of antibiotic potentiators and the impact of cannabidiol on the efficacy of tetracycline antibiotics against methicillin-resistant Staphylococcus aureus in livestock

Alexandra Doiron [1], Jessica Hursti [1], Nikesh Chander [1], Michelle Gandelman [1]

[1] University of Ottawa, Ottawa, Ontario, Canada K1N 6N5

Antibiotic resistance occurs when bacteria mutate and develop resistant genes, posing an imminent threat to global health, as they reduce the treatment options for bacterial infections. This is especially problematic in livestock, where antibiotics are essential for producing safe foods. Resistant bacteria are able to survive in the by-products, and be transferred into the intestinal flora of humans. Cannabidiol (CBD) is a cannabinoid proven to have antibiotic potentiator effects in vitro. It is a potentially promising synergist to reduce antibiotic doses in vivo. Our objective is to investigate the implications of CBD used in conjunction with tetracycline to examine its effect on antibiotic efficacy against Staphylococcus aureus in biological systems. Thirty-two laboratory rats will be infected with a strain of $S$. aureus through subcutaneous injection. For consistent dosing, each rat will be presented with a piece of clear tape containing the mixture paste of CBD and tetracycline. The controlled group will include rats receiving a standard dose of tetracycline $(5 \mathrm{mg} / \mathrm{lb}$ bodyweight) and those receiving the reduced dose of antibiotic $(2.5 \mathrm{mg} / \mathrm{lb}$ bodyweight). Variable groups will receive the reduced dose of the antibiotic and $5 \mathrm{mg} / \mathrm{lb}$ bodyweight of CBD. Antibacterial activity will be analyzed following the repeated four days of dosing. Antibacterial resistance in livestock poses an imminent threat to human health. Utilizing CBD could decrease the necessity of larger antibiotic doses, thus reducing incidences of bacterial resistance. Limiting human consumption of resistant bacteria would reduce the burden of antibacterial resistance on the healthcare system.

Is hinokitiol the antimicrobial-free solution to Streptococcus pyogenes?

Sinan Kaka [1], Yunbo Jiang [1], Olamide Olanrewaju [1], Amir-Ali Golrokhian-Sani [1]

[1] Queen's University, Kingston, Ontario, Canada K7L 3N6

Streptococcus pyogenes is a highly infectious and deadly bacterium in the streptococcus family, causing respiratory and skin infections. Treatments include oral penicillin and macrolides; however, macrolide-resistant S. pyogenes has begun to develop. Hinokitiol, a beta-thujaplicin, has been thought to be an alternative solution as it has a low occurrence of antimicrobial 
UNDERGRADUATE RESEARCH IN NATURAL AND CLINICAL SCIENCE AND TECHNOLOGY (URNCST) JOURNAL Read more URNCST Journal articles and submit your own today at: https://www.urncst.com

resistance (AMR), and it is effective against a family member of $S$. pyogenes called $S$. pneumoniae. In mice infected with $S$. pneumoniae, hinokitiol showed anti-bacterial, antioxidant and anti-inflammatory results in their respiratory tracts. It also had a low prevalence of AMR, so it is proposed that hinokitiol may be effective on a biologically similar bacterium, $S$. pyogenes and cause minimal AMR. Controlled mice trials were carried out to examine the effects of hinokitiol on multiple aspects of $S$. pyogenes. Control mice were split into an uninfected and infected control group to gauge the healthy mouse and the maximal effects of $S$. pyogenes. The trial mice were divided into three dosage groups (i.e. 1-dose, 2-dose, and 3-dose) to see the effects of hinokitiol in relation to dosage. Previous studies have demonstrated the efficacy of hinokitiol in treating bacterial infections caused by S. pneumoniae with decreased AMR. Since S. pyogenes and S. pneumoniae are in the same family, one can conclude that hinokitiol will have the same effect on S. pyogenes as it did on S. pneumoniae. However, further experiments should be conducted to support this hypothesis.

Development of a predictive diagnostic strategy for antimicrobial resistance Brandon Yu [1], Michael Trinh [2], Subaita Rahman [2]

[1] University of Toronto Scarborough, Scarborough, Ontario, Canada MIC 1A4

[2] University of Toronto St. George, Toronto, Ontario, Canada M5G

Prescribing antibiotics is commonplace in healthcare systems worldwide as a means to combat illness. However, the excessive, and often unnecessary administration of antibiotics has contributed towards a growing health crisis: antimicrobial resistance (AMR). In 2016, the Center for Disease Control and Prevention estimated the prescription of over 47 million antibiotic courses a year, comprising the $30 \%$ of antibiotics recommended annually. This trend of increasing risk poses AMR to be a future global health threat. Here we propose Resistome Evolutionary Prediction followed by CRISPR for Evolved Strains (REPCES), a cost effective and flexible framework for providing insight on the evolution of AMR in specific bacteria of interest. This proactive and scalable strategy relies on principles common to synthetic biology: scalability, flexibility, and deployability. This framework comprises five phases: each of which contributes to two deliverables. First, to identify the bacterial species of interest (SOI) and second, to discriminate between bacterial strains that have arised through mutations in resistance genes.

The use of the $\lambda$ bacteriophage to neutralize the pathogenic effects of shiga toxins from Escherichia coli to combat antimicrobial resistance

Jessica Karlovcec [1], Emma Veres [1], Brendan Paget [1]

[1] University of Guelph, Guelph, Ontario, Canada N1G 2 WI

Resistance to antibiotic drugs is becoming a widespread global health crisis and is exponentially increasing, estimating a total of 10 million deaths annually by the year 2050. An example of this is seen in certain strains of Escherichia coli (E. coli) bacteria which have become resistant to antibiotic drugs and thrive without competition. Pathogenic effects of these $E$. coli, such as gastrointestinal disease and, in severe cases, death, are caused by the Shiga toxins they produce. Instead of attempting to kill the pathogens, we propose altering the bacterial genome of E. coli, in ways to neutralize the toxins they produce. Our proposed approach would exploit homologous recombination via phage therapy to incorporate genetically modified DNA into the $E$. coli genome. Following DNA incorporation, the genetically modified $E$. coli will express globotriaosylceramide $\left(\mathrm{Gb}_{3}\right)$ receptors on their cell surface, functioning to neutralize any Shiga toxins produced, thereby reducing the pathogenic effects of E. coli.

The use of CRISPR-dCas9 system to combat antimicrobial resistance and virulence in Staphylococcus aureus Kaila Gabriel [1], Erin Anderson [1], Nicole Dudek [1]

[1] University of Guelph, Guelph, Ontario, Canada N1G 2W1

The rise of antibiotic resistant bacteria has become a challenge for the scientific and healthcare community in recent years. As resistance towards common antibiotics grows, there is a need to find a solution. Staphylococcus aureus, specifically Methicillin-Resistant Staphylococcus aureus (MRSA) is one such resistant bacteria. MRSA possesses two genes that allow virulent factors to proliferate and enables resistance to antibiotics, specifically Beta-Lactams. The mecA gene encodes Penicillin Binding Protein 2A (PBP2A), a transpeptidase that helps synthesize the bacterial cell wall. PBP2A is able to resist Beta-Lactam antibiotics, as it has a low affinity for binding to their ring-like structure. Thus PBP2A is unaffected in the presence of antibiotics and can continue cell wall synthesis. The Accessory Gene Regulatory (agr) gene is another factor,

Ngo et al. | URNCST Journal (2021): Volume 5, Issue 3

DOI Link: https://doi.org/10.26685/urncst.251

Page A4 of A11 
UNDERGRADUATE RESEARCH IN NATURAL AND CLINICAL SCIENCE AND TECHNOLOGY (URNCST) JOURNAL Read more URNCST Journal articles and submit your own today at: https://www.urncst.com

essential for the proliferation of MRSA bacteria, as it aids in the synthesis of virulent factors. Through the use of the CRISPR-dCas9 system technology, we propose to down-regulate both the mecA and $\operatorname{agr}$ genes, as a means of weakening MRSA bacteria. A synthesized plasmid containing CRISPR-dCas9 systems, with specificity for the promoter sites on the $m e c A$ and $a g r$ genes will be transformed into the MRSA genome. The newly modified S. aureus will be colonized on both a group of mice who have not been administered antibiotics, and a group who will be administered antibiotics, and the degree of infection will be monitored on each mouse. The loss of virulent producing factors, combined with the inhibition of the mecA mechanism responsible for antibiotic resistance is hypothesized to result in a damaged bacterial cell wall and subsequent weakening of the bacteria, allowing for clearance of the remainder of the pathogen by the immune system.

SiRNA-Mediated silencing of antifungal resistance genes

Katelyn Wang [1], Will Jeong [1], Alston Lo [1], Sean Jeong [1]

[1] University of Toronto St. George, Toronto, Ontario, Canada M5G

Antifungal resistance (AFR) is an underrepresented issue that threatens both global health and food security. For instance, Fusarium graminearum (Fg), the phytopathogen responsible for the devastating cereal fungal disease Fusarium head blight, has exhibited a continual increase in AFR over the last several years. A common feature of many pathogenic fungi is their ability to produce RNA induced silencing complexes (RISC) to protect against mycoviruses, thereby silencing the expression of targeted genes. Herein, we aim to create a genetically modified mycovirus which can silence AFR genes by leveraging RISCs. To investigate the potential effect of mycoviruses on AFR, Fg will be infected with a modified Fusarium graminearum deltaflexivirus 1 (mFgDFV1) that contains a $60 \mathrm{nt}$ segment from $F g A B C 3$, an azole resistance gene. $\mathrm{mFgDFV} 1$ will be produced in Saccharomyces cerevisiae via an episomal plasmid and then purified using an aqueous two-phase system. The efficacy of this treatment will be evaluated by comparing $\mathrm{MIC}_{50}$ values between $\mathrm{Fg}$ groups sprayed with mFgDFV1, wild type FgDFV1, and water. It is expected that Fg treated with $\mathrm{mFgDFV} 1$ will have a lower MIC , $_{0}$, the RISC complexes produced in response to $\mathrm{mFgDFV} 1$ will silence $\mathrm{FgABC} 3$.

Inducing germination of NAP1/B1/027 Clostridioides difficile spores as a means of increasing susceptibility to $70 \%$ isopropyl alcohol

Eve Harrison [1], Mohammed Ahmed [2], Judy Sobh [2], Nicole Oancea [2]

[1] Queen's University, Kingston, Ontario, Canada K7L 3N6

[2] University of Ottawa, Ottawa, Ontario, Canada K1N 6N5

With increasing rates of Clostridioides difficile infections (CDIs) in healthcare settings, and an absence of a safe and effective disinfecting regimen, CDIs continue to wreak havoc on healthcare systems and contribute to antimicrobial resistance (AMR) through inherent traits and horizontal gene transfer. In fact, an alarming emergence and spread of $C$. difficile antibiotic resistance is currently complicating treatment programs. Due to a lack of adequate disinfection methods-one of the key strategies in combating antibiotic resistant pathogens - the spread of resistance among $C$. difficile bacteria is only worsening. This study proposes a novel, economic, and safe disinfection method to effectively eliminate $C$. difficile spores in healthcare settings as opposed to current sporicidal agents such as sodium hypochlorite, which is corrosive and a health hazard. The proposed method entails using a combination of a germinating solution of $0.1 \% \mathrm{w} / \mathrm{v}$ sodium taurocholate, $0.2 \% \mathrm{w} / \mathrm{v}$ glycine, and distilled water, made to mimic the intestinal bile acid environment that induces germination, along with a subsequent application of $70 \%$ isopropyl alcohol that would otherwise be ineffective on bacteria in a spore state. Germination results in the degradation of the bacterial spore to a vegetative state, which increases $70 \%$ isopropyl alcohol's effectiveness as a permeating biocide. Thereby resulting in the elimination of $C$. difficile bacteria and serving to slow the spread of antibiotic resistant DNA.

Using CRISPR-Cas9 complex to eliminate efflux pumps in multi-drug resistant typhoidal salmonella; as an approach to increase susceptibility to antibiotics formerly known to be ineffective

Ayshin Mehrabi [1], Ernest Li [1]

[1] Ryerson University, Toronto, Ontario, Canada M5B $2 \mathrm{K3}$

An unending battle between humans and bacterial infections is bacteria's ability to evolve and resist antibiotic treatments. This resistance is achieved by the development of numerous resistance mechanisms, rooting from the expression of Antimicrobial resistance genes (AMR) in the bacterial genome. Salmonella Typhi enterica is a multi-drug resistant bacteria that causes typhoid fever and gastroenteritis and depicts these resistance mechanisms by expressing several AMR genes that code for drug

Ngo et al. | URNCST Journal (2021): Volume 5, Issue 3

Page A5 of A11

DOI Link: https://doi.org/10.26685/urncst.251 
UNDERGRADUATE RESEARCH IN NATURAL AND CLINICAL SCIENCE AND TECHNOLOGY (URNCST) JOURNAL Read more URNCST Journal articles and submit your own today at: https://www.urncst.com

efflux pumps. This paper aims to silence the AMR genes, which code for efflux pumps in S. Typhi, using CRISPR Cas-9 Complex as an approach to increase susceptibility to antibiotics formerly known to be ineffective. CRISPR Cas-9 can be designed in a highly specific manner to target any desired gene in a given organism and is less costly than other genetic modification methods. It contains a nuclease which could induce a double-stranded DNA break and a single- nucleotide guide RNA (sgRNA) that is designed based on the gene in question. Once the AMR genes are silenced, the bacteria could potentially become vulnerable to antibiotic treatments that were previously ineffective. The CRISPR method is not only specific for this type of bacteria, rather any bacteria with AMR genes responsible for the resistance mechanisms. With the use of such programmable tools like CRISPR the potential is uplifting and could be very beneficial in the world of science.

\title{
$\underline{\text { Upper Division }}$
}

\author{
Addressing azithromycin wastewater contamination through transfected Coelastrum sphaericum in high-rate algal \\ ponds to prevent antibiotic resistance \\ Muizz Hussain [1], Muhammadhasan Nasser [1], Shangi Vijenthira [1] \\ [1] McMaster University, Hamilton, Ontario, Canada L8S 4L8
}

Antibacterial resistance poses a modern global health threat and novel means of combating it are required. Azithromycin is a widely-used antibiotic and immunomodulatory medication to which resistance is particularly concerning, as it also confers resistance to other widely-used antibiotics. Additionally, many antibiotics, including azithromycin, are found in wastewater and contribute to the development of antibacterial resistance. As such, new forms of wastewater treatment, such as more efficient high-rate algal ponds (HRAPs), are needed. Coelastrum sphaericum (C. sphaericum) algae transfected with EreA to produce erythromycin esterase type I will remove active azithromycin from wastewater at a higher rate than wild-type $C$. sphaericum in a laboratory setting. The results of the proposed study could inform future research in the implementation of HRAPs containing transfected algae to remove antibiotics from wastewater. The plasmid pIP1100, containing EreA, will be extracted from Escherichia coli using a midiprep kit. This plasmid will be transfected into C. sphaericum using biolistic technology. To confirm enzyme production in the algae, a quantitative western blot will be performed. The rate of removal of azithromycin will be assessed through high-performance liquid chromatography, with metabolite analyses done through mass spectrometry. Additionally, bacteriostatic and toxicity assessments will be performed to determine efficacy and safety.

\section{The use of apis mellifera colonies as novel bioindicators for evaluating environmental antibiotic-resistant Clostridium difficile burden \\ Alison Hacker [1], Megan Cheng [1], Parnika Godkhindi [1], Rhea Jangra [1] \\ [1] McMaster University, Hamilton, Ontario, Canada L8S 4L8}

Antimicrobial resistance has become a major health and economic crisis and is caused by the overuse and misuse of antibiotics. While antimicrobial resistance is most commonly reported in healthcare settings, drug-resistant spores are frequently transmitted to the surrounding environment. The European honey bee, Apis mellifera, pollinates and surveys a large area of land around its hive. Given its ecological role, studies have shown that Apis mellifera can acquire antibioticresistant strains of bacteria from the surrounding environment. Likewise, recent data have demonstrated the potential of Apis mellifera colonies to serve as environmental bioindicators of various types of bacteria. In the present study, we propose using Apis mellifera colonies, spread across distinct environmental sites, to detect the emergence of drug-resistant $C$. difficile strains. We suggest isolating $C$. difficile strains from Apis mellifera intestinal tissue to evaluate the effectiveness of clinically relevant antibiotics. This novel study will help indicate emerging drug-resistance in specific regions, while also providing a framework for the detection of other potentially drug-resistant microbial strains.

Testing isopropanol tolerance in methicillin-resistant Staphylococcus aureus hospital strains Tina Kabir [1], Dhanyapriya Saravanan [1], Jannikaa Kathiramathamby [1]

[1] Western University, London, Ontario, Canada N6A $3 K 7$

Antimicrobial resistance (AMR) has been recognized as a global health concern for years. With more bacteria resistant to antimicrobial agents, treatment of common infections presents a struggle for healthcare professionals. During the ongoing COVID-19 pandemic, alcohol-based hand sanitizers are often overused. Recent studies show that some bacteria can develop tolerance to alcohol, such as isopropanol. Hence a concern arises that the extensive use of alcohol-based disinfectants will worsen the AMR problem. Methicillin-resistant Staphylococcus aureus (MRSA) is responsible for various healthcare-

Ngo et al. | URNCST Journal (2021): Volume 5, Issue 3

Page A6 of A11

DOI Link: https://doi.org/10.26685/urncst.251 
UNDERGRADUATE RESEARCH IN NATURAL AND CLINICAL SCIENCE AND TECHNOLOGY (URNCST) JOURNAL Read more URNCST Journal articles and submit your own today at: https://www.urncst.com

associated infections, leading to sepsis and death. This study aims to test the hypothesis that MRSA hospital strains will become more tolerant to isopropanol over 24 months. Two large hospitals in Ontario will be chosen to each provide two isolates every month, resulting in 96 total isolates. Alcohol tolerance of each MRSA isolate will be determined by exposure to $23 \%$ isopropanol (exposure to PBS as negative controls). After overnight incubation, the colony-forming units will be counted, the mean $\log 10 \mathrm{CFU}$ reduction for each isolate will be determined and compared among the isolates using the MannWhitney U-test. Subsequently, given that significant differences are detected, the following steps will be conducted to mimic MRSA spread in a hospital setting. Firstly, the survival rates of the alcohol-tolerant and alcohol-sensitive strains after exposure to $60-70 \%$ isopropanol will be compared. Moreover, mouse models for gut colonization will be created to study how the alcohol-resistant MRSA behaves in vivo. In conclusion, the proposed study will discover whether alcohol resistance is the next, yet undetected, global health concern.

Computational design and lab-based investigation of a novel small molecule inhibitor that targets CadA metal efflux pump activity in hospital methicillin-resistant Staphylococcus aureus

David Chen [1], Jason Wang [1], Ling Dzit Wong [1], Eugene Chung [1]

[1] Western University, London, Ontario, Canada N6A $3 K 7$

Metals have been used ubiquitously in hospitals for their antimicrobial properties. This includes coating exposed surfaces, surgical tools, and medical implant devices. While metals have been effective in controlling microbe populations, their heavy use has acted as a selection pressure for metal resistance in select strains of bacteria. One of these strains is methicillinresistant Staphylococcus aureus (MRSA), which causes more than 70,000 cases of bacteremia annually. MRSA is able to resist metals by flushing them out of the cytoplasm through CadA, an efflux pump found in the bacteria's cell wall. The CadA gene can be horizontally transferred via plasmids, allowing metal resistance to quickly spread in a hospital population. Due to CadA's ubiquity in MRSA, it presents as a promising target for small molecule inhibition. The present study investigates the computational design of Scinapsin, a novel small molecule inhibitor that binds and inactivates the catalytic site of CadA. An experimental protocol to verify the inhibitory properties of Scinapsin on MRSA isolates is also presented. If proven to be successful, our hope is that Scinapsin can be incorporated into disinfectants and help reverse heavy-metal resistance in hospital MRSA populations.

Small molecule inhibition of S-layer proteins in Clostridium difficile Colette Benko [1], Kristina Timcevska [1], Qianchen Jing [1], Kaitlin Lees [1]

[1] Western University, London, Ontario, Canada N6A $3 K 7$

Bacterial antibiotic resistance is a growing issue, particularly for Clostridium difficile, which colonizes the gut when the normal microbiota is disrupted through use of antibiotics or poor health. A novel method of targeting resistant bacteria is to reduce virulence, without altering survival or growth, thereby decreasing the selection pressure that usually selects highly resistant pathogens. Considering $C$. difficile is an opportunistic pathogen of the human and animal gut with extensive resistance, it is a prime candidate to be a target of this therapy. Furthermore, past literature suggests removal/disruption of $C$. difficile S-layers results in a lack of disease symptoms, while maintaining normal $C$. difficile colonization in hamsters' gut. We propose the development of novel small molecule inhibitors to target $C$. difficile S-layers to reduce symptoms resulting from bacterial infection and promote the reformation of a healthy microbiota during a $C$. difficile infection preceded by antibiotic use, particularly in patients with a history of past infections. We identified key conserved residues involved in the interaction between $C$. difficile S-layer protein subunits. Additionally, homology modeling allowed in silico drug development of two compounds that that may inhibit these interactions. Further development and validation of these compounds is discussed. S-layers are also present in a variety of other bacteria such as Clostridium Perfringens and Bacillus Anthracis; thus, this method can be applied to numerous other bacteria. Furthermore, these pathogens have high infection rates in livestock and thus may be particularly beneficial for the agricultural industry.

Bacteriophage-liposomal complex: A bi-therapy to target $S$. Pneumonia biofilm Samy Asraoui [1], David Jung [1], Antoine Gaudreau-Lapierre [1], Emran Alnahhas [1] [1] University of Ottawa, Ottawa, Ontario, Canada K1N 6N5

Streptococcus pneumoniae infection has been the leading cause of death for children under the age of five, and a contributing factor to the elderly and immunocompromised patients' mortality rates. Its ability to mutate and become resistant to some of the strongest antibiotics makes them difficult to treat and increases the risk of disease spread. Although the development of

Ngo et al. | URNCST Journal (2021): Volume 5, Issue 3

Page A7 of A11

DOI Link: https://doi.org/10.26685/urncst.251 
UNDERGRADUATE RESEARCH IN NATURAL AND CLINICAL SCIENCE AND TECHNOLOGY (URNCST) JOURNAL Read more URNCST Journal articles and submit your own today at: https://www.urncst.com

stronger antibiotics to treat such microbes may be an option, they pose a dangerous threat to the body and while vaccines for $S$. pneumoniae only cover some pneumococcal strains, they are unable to protect against non-vaccine serotypes. The medicine to fight against antimicrobial resistance that is also a viable treatment option has yet been found. Our study focuses on utilizing a bi-therapy system to target $S$. pneumoniae in biofilm, which is the site of emerging antibiotic resistant mutants. Using bacteriophage therapy and applying bacteriophage-antibiotic synergy, we hope to augment the potency of the treatment while lowering its side-effects. We expect that our $\mathrm{Cp}-1$ bacteriophage-liposomes complexes are specific to the $S$. pneumoniae to carry antibiotics to sites of infection. The therapy could ensure targeted bacterial lysis and site-directed delivery of low-dose drugs to decrease the toxicity effect of the antibiotics. Once the efficacy is established and is proven to be significant, we could move on to testing its potency in $\mathrm{CBA} / \mathrm{J}$ mice models before bringing this therapy to animal trials then human clinical trials.

A new era of antibiotic susceptibility testing: Using MALDI-TOF mass spectrometry for detection of Staphylococcus aureus resistance Tanvi Rathi [1], Sakshi Kharbanda [1]

[1] Queen's University, Kingston, Ontario, Canada K7L 3N6

One of the greatest challenges faced in bacterial testing is the lack of rapid testing methods available to identify antibiotic resistance. Current testing methods for detecting antibiotic susceptibility still relies on using antibiotic impregnated discs and strips which take between 24 and 48 hours post organism identification leaving practitioners no choice but to use empiric broad spectrum antibiotics rather than narrow-spectrum antibiotics with better outcomes. The last decade of Microbiology has seen major shifts in the way bacteria are identified with the widespread implementation of Matrix Assisted Laser Desorption Ionization Time-of-Flight (MALDI-TOF). MALDI-TOF has reduced the time it takes to identify bacteria from clinical specimens, with blood cultures being identified in as little as 4 hours after flagging positive, resulting in better patient outcomes and reduced length of stays in hospitals. MALDI-TOF creates a protein fingerprint of bacteria for identification. Changes in proteins like those seen in some antibiotic resistance phenotypes should theoretically be detectable using MALDI-TOF but have yet to be incorporated into clinical testing. Our goal is to create a MALDI-TOF mass spectrometry (MS) output for the antibiotic susceptibility testing (AST) in strains of Staphylococcus aureus - specifically strains of methicillin-resistant $S$. aureus (MRSA) - that can be incorporated into routine clinical use.

An ultra high-throughput method for the generation and screening of novel antibiotic nonribosomal peptides Meera Patel [1], Anna Dvaladze [1]

[1] University of Toronto Scarborough, Scarborough, Ontario, Canada MIC 1A4

Antimicrobial resistance (AMR) is a looming global health crisis that is rendering currently available antibiotics increasingly ineffective. Methods for rapid and affordable development of novel antibiotics are greatly needed to combat AMR. Microorganisms are well-known reservoirs of antimicrobial compounds, using nonribosomal peptide synthases (NRPSs) to produce a wide variety of structurally and functionally diverse antibiotics. NRPSs are highly modular, with wellcharacterized domains able to assemble and modify amino acids in a sequential manner. This has made them attractive targets for directed evolution approaches to generate antibiotic analogues with novel or improved activities. These attempts are hindered by the frequent abolishment of NRPS activity that occurs due to incompatible mutations, but high-throughput methods have considerable potential for catching the relatively few functional NRPS mutants and assessing antibiotic activities. We propose combining directed evolution with ultra high-throughput droplet microfluidics as a method for the rapid generation and screening of novel antibiotics. This will be demonstrated on the NRPS for Gramicidin S, and assayed against carbapenem resistant E. coli. The method applied in this study can theoretically be applied to more complicated NRPSs with modifications, and can provide insight into the requirements for functional NRPS mutants and therefore aid in future rational antibiotic design.

Investigating if polyphenol exposure increases polyphenol resistance in river microbial communities William Stewart [1], John Perrier [1]

[1] University of Guelph, Guelph, Ontario, Canada N1G 2W1

River microbial communities are often exposed to unnatural levels of antimicrobials imparted by the dumping of wastewater. Winery wastewater (WWW) has been found to have very high levels of polyphenols, a compound that is known to have antimicrobial activity. Many wineries treat wastewater on site and the amount of polyphenol released in the effluent is not

Ngo et al. | URNCST Journal (2021): Volume 5, Issue 3

Page A8 of A11

DOI Link: https://doi.org/10.26685/urncst.251 
UNDERGRADUATE RESEARCH IN NATURAL AND CLINICAL SCIENCE AND TECHNOLOGY (URNCST) JOURNAL Read more URNCST Journal articles and submit your own today at: https://www.urncst.com

closely monitored. The impact that this effluent has on river microbial communities is not well understood. This study aims to quantify the effect long term exposure to polyphenols derived from Vitis vinifera has on the development of polyphenol resistance within river microbial communities and identify any changes in community composition. Microbial communities from three different Niagara region waterways will each be grown in two Winogradsky columns containing non-lethal concentrations of polyphenol, as well as a river water control. Community antimicrobial resistance will then be measured with heterotrophic plate counts onto soy extract agar containing $1080 \mathrm{mg}$ tannic acid equivalent (TAE/ml) polyphenol extract. Community composition will be determined before and after polyphenol treatment using the MiSeq platform developed by Illumina and analysing using MOTHUR with subsequent statistical analysis done in R. Should $V$. vinifera derived polyphenols demonstrate a significant impact on river microbial communities, future studies will be required to understand the prevalence of polyphenol contamination in WWW effluent of the Niagara region.

Combating antimicrobial resistance: Assessing efflux pump deficient environments in Neisseria gonorrhoeae and the masking effect on antimicrobial-resistant mutations

Kaitlyn Jackson [1], Tiffany Ayoub [1], Julie Richmond [1], Julia Pearson [1]

[1] University of Guelph, Guelph, Ontario, Canada N1G 2W1

Antimicrobial resistance (AMR) is a global emergency that involves the process of microbes gaining resistance to antimicrobials. A specific example of this is Neisseria (N.) gonorrhoeae gaining resistance to azithromycin, which can be caused by mutations at ribosomal sites. New research suggests that manipulating the bacteria to create a drug efflux pump deficiency will "mask" the effects AMR mutations when introduced to antibiotic drugs, compared to that of a drug efflux pump proficient environment. This proposal aims to investigate the effects of a drug efflux pump deficient environment compared to a drug efflux pump proficient environment on azithromycin drug efficacy in N. gonorrhoeae with an AMR ribosomal mutation. It is hypothesized that AMR mutations can be masked through gene knock out causing MtrCDE efflux pump deficient environments of $N$. gonorrhoeae. Induced mutations for resistance to azithromycin will take place in $N$. gonorrhoeae strains using CRISPR genome editing, followed by the creation of a MtrCDE drug efflux pump deficient environment using CRISPR-Cas9 to delete the $m t r E$ gene. Resistance will be determined using disk diffusion and zone of inhibition. Preventing the progression of AMR requires the exploration of bacterial mechanisms that promote resistance and subsequently prohibiting them. The inhibition of drug efflux pumps has been previously demonstrated to aid in the repression of AMR. This leads to the proposed investigation of efflux pump deficiency in the presence of AMR mutations, potentially creating the masking effect of interest. The concept of masking could be a gateway towards effective strategies to combat AMR.

Resurrecting the dead: Mitigating efflux-pump inhibitor toxicity using a liposomal delivery system to recover efficacy of antimicrobial drugs

Prachi Ray [1], Kha Nguyen [1], Sukriti Sachdev [1], Truong Nguyen [1]

[1] University of Toronto St. George, Toronto, Ontario, Canada M5G

Antimicrobial resistance (AMR) has become concerningly prevalent on a global scale as many infectious agents have evolved to evade antimicrobials effects, making it difficult to treat infectious diseases. Pseudomonas aeruginosa is a multiresistant bacteria that requires urgent attention as it is detrimental in lung infections, particularly in individuals with cystic fibrosis. Activity of membrane-embedded efflux pumps, such as the MexAB-OprM pump, is a principal mechanism by which bacterial species become resistant to antimicrobials. Efflux pump inhibitors (EPIs) have recently emerged as a strategy to prevent the expulsion of administered antimicrobials, thereby resensitizing resistant bacteria to antibiotics. Phenylalaninearginine $\beta$-naphthylamide $(\mathrm{PA} \beta \mathrm{N})$ is an EPI that inhibits a number of different pumps, including the MexAB-OprM efflux system. Despite EPIs providing a partial solution to AMR, they have been shown to be toxic to humans, which has impeded their entry into clinical application. We propose that by inserting the PA $\beta \mathrm{N}$ into a liposomal delivery system, the cytotoxic effects against human cells will be lowered without decreasing the EPI's inhibitory activity. To test this, resistant $P$. aeruginosa strains will be administered with liposomal-encased PA $\beta \mathrm{N}$ and ampicillin to measure efflux activity and inhibited growth, whereas human pulmonary epithelial cells will be exposed to liposomal-encased PA $\beta \mathrm{N}$ to study cell viability. If effective, EPIs may become a potential therapeutic to combat AMR in infections by reviving the use of antimicrobials that have become ineffective. Restoring the activity of already approved antibiotics through potential coadministration with liposome-encapsulated EPIs will be a cost-effective and worthwhile approach to combat AMR.

Ngo et al. | URNCST Journal (2021): Volume 5, Issue 3

Page A9 of A11

DOI Link: https://doi.org/10.26685/urncst.251 
UNDERGRADUATE RESEARCH IN NATURAL AND CLINICAL SCIENCE AND TECHNOLOGY (URNCST) JOURNAL Read more URNCST Journal articles and submit your own today at: https://www.urncst.com

\author{
Disruption biofilm formation and antibiotic resistance in Pseudomonas aeruginosa using phage-delivered sensitivity \\ cassettes \\ Madelyn Fischer [1], Mitchell Shorgan [1], Isabell Pitigoi [2], Courtney Ostromecki [2] \\ [1] University of Guelph, Guelph, Ontario, Canada N1G 2W1 \\ [2] Queen's University, Kingston, Ontario, Canada K7L 3N6
}

Despite antimicrobial resistance (AMR) topping the list of global health concerns, the development of novel antibiotics has been nearly abandoned due to strict regulations and dwindling economic incentives in the pharmaceutical industry. There is a critical need for alternative strategies to treat multidrug resistant (MDR) pathogens like Pseudomonas aeruginosa, a leading cause of nosocomial infections. Here, we aim to target adaptive resistance in $P$. aeruginosa biofilms by inducing hypersensitivity to existing antibiotics through phage-delivery of a particular gene cassette. Previous studies have suggested that the rpoS gene is repressed in P. aeruginosa biofilms and that its deletion is correlated with hypervirulence, increased biofilm thickness and antibiotic resistance. In this protocol, we explore the potentially therapeutic effects of rpoS hyperexpression for biofilm disruption and increased tobramycin sensitivity. Phagemids containing rpoS, its accompanying promoter, and a mercury resistance gene are delivered by P1 bacteriophages to a biofilm to be dispersed through horizontal gene transfer (HGT). Mercury is then administered to induce selective pressure for HGT, based on the competitive advantage that the resistance gene confers. Varying the strength of the promoter in the phagemid allows us to compare the effect of different levels of rpoS expression on biofilm organization. Antibiotic sensitivity is then quantified by obtaining viable cell counts following treatment with tobramycin. We expect to identify an ideal level of rpoS expression that minimizes both biofilm formation and tobramycin resistance. This would demonstrate a potential for phage-mediated hypersensitization of $P$. aeruginosa that is adaptable to more practical settings, such as in situ on hospital surfaces.

\title{
Conflicts of Interest
}

The authors declare that they have no conflict of interests.

\section{Authors' Contributions}

CN: President of the Undergraduate Research Initiative, served on the planning committee for the USCC, drafted the conference abstract booklet, and gave final approval of the version to be published.

RK: President of Scinapse and Chair of the USCC planning committee, assisted authors with their abstract submissions, drafted the conference abstract booklet, and gave final approval of the version to be published.

LM: Senior Advisor to the President of Scinapse, served on the planning committee for the USCC, drafted the conference abstract booklet, and gave final approval of the version to be published.

\section{Acknowledgements}

We want to acknowledge the entire Scinapse Provincial Team for playing an integral role in making this year's USCC a big success. The team that helped make this competition possible includes: Rebecca Krnel as President of Scinapse and Chair of the planning committee, Linda Mardiros as Senior Advisor to the President, Clarissa Ngo as President of URI, Justen Choueiry as Vice-President of Finances of URI, Dilpreet Bajwa as Communications Team Lead, Momina Ejaz as Communications Director, Laura Mardiros as Provincial Coordinator, Misha Kaniyath and Amanda Vandewint as Graphic Designers, Varis Gupta as Mentorship Lead, Marilou Poitras as Scientific Advisor, Antony El-Khoury as Operations Team Lead, Phanisri Mudunuri as Project and Statistics Coordinator, Isaac Kuk as Sponsorship and Statistics Coordinator, Darius Stamatakos and Justin Thomas as uOttawa Campus Leaders, and Jasmine Candeliere as Event Manager and Logistics Coordinator.

The USCC would not have been successful without the contribution and work of the multiple different chapters of the Scinapse USCC situated across other universities in Ontario.

We want to acknowledge all the professors and graduate students that participated as judges for the competition. Your valuable time and feedback to the participants has had a positive impact on their future success.

\section{Funding}

The Scinapse USCC is funded by the Undergraduate Research Initiative and contributions from the University of Ottawa Faculty of Science and the Faculty of Medicine. 
UNDERGRADUATE RESEARCH IN NATURAL AND CLINICAL SCIENCE AND TECHNOLOGY (URNCST) JOURNAL Read more URNCST Journal articles and submit your own today at: https://www.urncst.com

Article Information

Managing Editor: Jeremy Y. Ng

Article Dates: Received Feb 17 21; Published Mar 0321

\section{Citation}

Please cite this article as follows:

Ngo C, Krnel R, Mardiros L. Scinapse 2020-2021 Undergraduate Science Case Competition: Antimicrobial resistance: A global health crisis. URNCST Journal. 2021 Mar 03: 5(3). https://urncst.com/index.php/urncst/article/view/251

DOI Link: https://doi.org/10.26685/urncst.251

\section{Copyright}

(C) Clarissa Ngo, Rebecca Krnel, Linda Mardiros. (2021). Published first in the Undergraduate Research in Natural and Clinical Science and Technology (URNCST) Journal. This is an open access article distributed under the terms of the Creative Commons Attribution License (https://creativecommons.org/licenses/by/4.0/), which permits unrestricted use, distribution, and reproduction in any medium, provided the original work, first published in the Undergraduate Research in Natural and Clinical Science and Technology (URNCST) Journal, is properly cited. The complete bibliographic information, a link to the original publication on http://www.urncst.com, as well as this copyright and license information must be included.

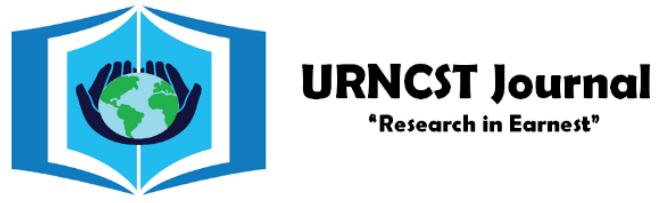
Funded by the
Government of Canada

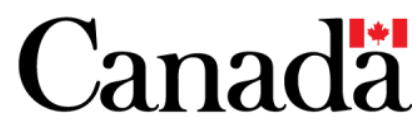

Do you research in earnest? Submit your next undergraduate research article to the URNCST Journal!

| Open Access | Peer-Reviewed | Rapid Turnaround Time | International |

| Broad and Multidisciplinary | Indexed | Innovative | Social Media Promoted |

Pre-submission inquiries? Send us an email at info@urncst.com | Facebook, Twitter and LinkedIn: @URNCST

Submit YOUR manuscript today at https://www.urncst.com!
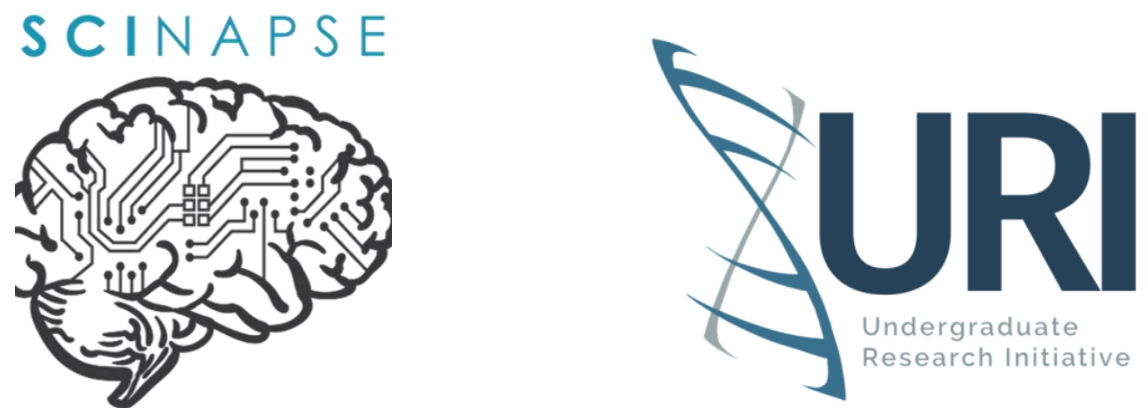

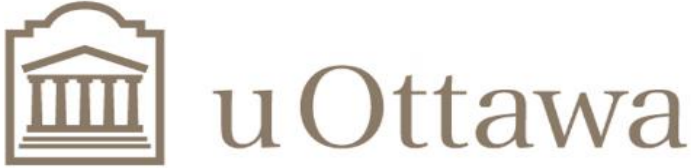

Faculté de médecine

Faculty of Medicine
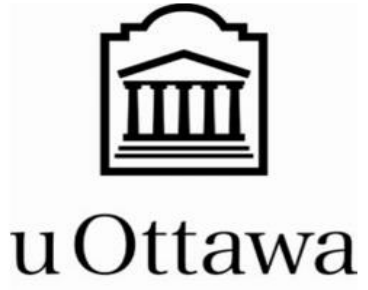

Faculté des sciences Faculty of Science 